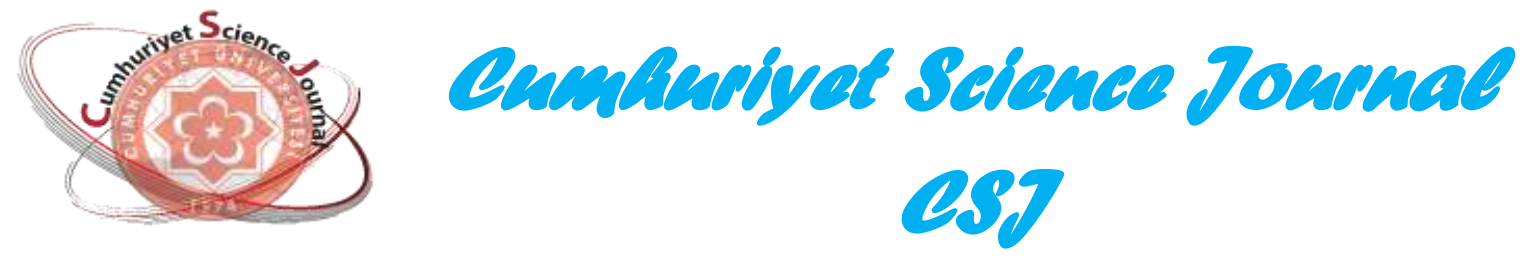

\author{
Pirina Kullanılarak Adsorpsiyon Prosesinde Renk Giderimi \\ Muhammed Kamil ÖDEN ${ }^{1 *}$, Serkan ŞAHİNKAYA ${ }^{2}$, Sezen KÜÇÜKÇONGAR ${ }^{3}$ \\ ${ }^{1}$ Selçuk Üniversitesi, Sarayönü Meslek Yüksek Okulu, Çevre Teknolojileri Bölümü, Konya. \\ ${ }^{2}$ Nevşehir Hacı Bektaşi Veli Üniversitesi, Müh. ve Mim. Fak., Çevre Mühendisliği Bölümü, Nevşehir. \\ ${ }^{3}$ Selçuk Üniversitesi, Mühendislik Fakültesi, Çevre Mühendisliği Bölümü, Konya.
}

\begin{abstract}
Özet: Zeytin ve zeytinyağı özellikle Akdeniz ülkelerinde üretilen önemli tarım ürünleridir. Türkiye'de Ege, Marmara, Akdeniz, Güneydoğu Anadolu Bölgeleri’nde zeytin ağacı yetiştirilmektedir. Bu kadar geniş bir uygulama sahasına sahip olan zeytin endüstrisinin faaliyetleri sırasında oluşan bazı üretim atıkları bulunmaktadır. Zeytin ağacı yetiştirme sırasında her ağacın yıllık yaklaşık $25 \mathrm{~kg}$ 'a kadar yan ürün (çerçöp, dal, yaprak vb.) oluşturduğu tahmin edilmektedir. Zeytin atığı ürünlerinin tip ve miktarı üretim teknolojileri ve çalışma verimliliğine göre değiş̧im göstermektedir. Zeytinin ağaçtan toplanıp zeytinyağı elde edilene kadar geçen süreçte elde edilen zeytin yaprakları, dalları, pirina ve karasu temel yan ürünlerdir. Endüstriyel faaliyet sırasında ise çekirdek, kabuk ve posa gibi materyalleri içeren atığa da pirina denilmektedir. Yağ ekstrakte edilirken uygulanan prosedüre göre elde edilen pirinanın da nem ve yağ içeriği değişmektedir. Deneylerde ise kuru halde hazırlanmış pirina kullanılmıştır.
\end{abstract}

Bu çalışmada laboratuvar ortamında hazırlanan Everzol Yellow 3RS içeren sentetik atıksudan adsorban madde olarak zeytin atığı (pirina) kullanılarak renk giderimi araştırılmıştır. Adsorbanın etkinliğini kanıtlayabilmek üzere süreye, doza, hıza, sıcaklığa ve pH'ya bağlı olarak optimum denge şartları belirlenmiştir. Adsorpsiyon işlemleri neticesinde 150 dakika temas süresi, $250 \mathrm{rpm}$ karıştırma hızı, $\mathrm{pH} 7,5$ ve $25^{\circ} \mathrm{C}$ sıcaklık değerlerinde adsorban/boya oranı olarak 0,6 g/250 mL (\%80'nin üzerinde giderim) elde edilmiştir.

Anahtar Kelimeler: Adsorpsiyon, Pirina, Everzol Yellow 3RS, Renk Giderimi, Zeytin Atığ

\title{
Colour Removal with Adsorption Process Using Pomace
}

\begin{abstract}
Olive and olive oil are important agricultural products produced especially in Mediterranean countries. Olive tree is grown in Aegean, Marmara, Mediterranean and Southeastern Anatolia regions in Turkey. Some production wastes are caused by the activities of olive industry which has a rich application area. It is estimated that in the course of growing, each olive tree annually generates about $25 \mathrm{~kg}$ of by product (sweeps, branches, leaves etc.). The type and amount of Pomace products vary according to production technologies and work productivity. In the process starting from the picking up of olives from the tree to the production of its oil, the basic emergent by products are olive leaves, branches, pomace and wastewaters of olive oil. The waste which includes materials such as seed, crust, pulp in the course of industrial activities is also called pomace. The humidity and olive content of the pomace obtained varies according to the procedure applied in the extraction of oil. In the experiments, dry-prepared pomace was used.

In this study colour removal was examined from synthetic color wastewater containing Everzol Yellow 3RS prepared in laboratory process by using pomace as an adsorbent. In order to prove the effectiveness of the adsorbent, optimum equilibrium conditions was determined dependently on contact time, dosage, speed, temperature and $\mathrm{pH}$. As a result of adsorption processes, 150 min. contact time, $250 \mathrm{rpm}$ mixing speed, $\mathrm{pH} 7,5$, $25^{\circ} \mathrm{C}$ temperature and $0,6 \mathrm{~g} / 250 \mathrm{~mL}$ adsorbent/dye ratio (over $80 \%$ removal efficiency) were determined.
\end{abstract}

Keywords: Adsorption, Pomace, Everzol Yellow 3RS, Color removal, Olive Waste

\footnotetext{
* Corresponding author. Email address: muhammedkoden@selcuk.edu.tr

http://dergipark.gov.tr/csj @2016 Faculty of Science, Cumhuriyet University
} 


\section{GíRİs}

Günümüzde artan tüketim ihtiyacı ve buna paralel olarak da oluşan atık miktarları ve çeşitliliği de artmaktadır. Çevresel bir kirlilik parametresi olan renk başta estetik açıdan olmakla birlikte fiziksel, kimyasal ve biyolojik etkilere sebep olabilmektedir. Özellikle tekstil endüstrisinden kaynaklanan boyalı kirlenmiş suların birçok sebepten dolayı arıtılması zor olmaktadır [1]. Tekstil endüstrisi ile birlikte kozmetik, matbaacılık, boyama, gıda boyaları ve kâğıt imalat sanayilerindeki atıksular da boya içerebilmektedir. $\mathrm{Bu}$ renkli atıksular, yüzey suyuna ve yeraltı suyu sistemlerine karışabilmekte ve daha sonra içme suyuna da aktarılabilmektedir. Bu boyalar alerjik dermatite, cilt tahrişine, kansere ve mutasyonlara neden olabilmektedir [2]. Suda $0,005 \mathrm{mg} / \mathrm{L}$ konsantrasyonundan daha yüksek olan boya gözle algılanabildiği için özellikle estetik yerlerde bu konsantrasyonu aşan miktarı uygun bulunmamaktadır. Ayrica bu renkli materyaller suda 1şık geçirgenliğini düşürmekte, yaşamlarını fotosentetik olarak yürüten canlıları olumsuz bir şekilde etkilemektedir [3].

Atık sulardan boyar maddelerin giderilmesi için birçok kimyasal ve biyolojik yöntemler kullanılmaktadır. Boyaların kompleks aromatik yapılarından dolayı birçok boya biyolojik olarak bozunmaz ve yükseltgenmeye karşı dirençlidir. Ayrıca boyar maddelerin uzaklaştırılması için kimyasal ve fiziksel yöntemlerin birçoğu maliyetlidir. $\mathrm{Bu}$ da araştırmacıları adsorpsiyon yöntemi gibi ucuz, ekonomik ve güvenilir bir yöntem kullanmaya teşvik etmiştir. Adsorpsiyonun diğer yöntemlere göre atık içermemesi ve seyrek çözeltilerden bile tam olarak boya arıtımını sağlaması gibi üstünlükleri vardır [4,5]. Adsorpsiyon sistemlerinde birçok farklı adsorban kullanılmaktadır. Bunlar arasında bor cevheri [6], uçucu kül [7], ham kil [8], kitosan [3,5], bor zenginleştirme atığı [9], pirina $[10,11,12,13] \mathrm{vb}$. gibi birçok malzeme bulunmaktadır. Pirina zeytinyağı endüstrisi yaprak, dal, zeytin çekirdeği vb. gibi kısımlarından oluşan atığa denilmektedir. Pirina ile atıksulardan kirletici giderimi üzerine yapılan birçok araştırma bulunmaktadır. Pirina ile yapılan bir boya giderim çalışmasında adsorpsiyon için optimum şartların $\mathrm{pH} 3$ ve $50{ }^{\circ} \mathrm{C}$ olduğu belirlenmiş; incelenen tüm şartlar altında, pirina üzerine Remazol brillant blue R'nin maksimum adsorpsiyonunun $\% 89,15$ ve $\% 100$ arasinda olduğu ve $\mathrm{qe}=23,63 \mathrm{mg} / \mathrm{g}$ belirlenmiştir [11]. Başka bir çalışmada zeytinyağı fabrikası atıksuyu analiz edilmiş ve daha sonra funguslar ile aerobik olarak muamele edilen çalışmada KOI, fenol, renk ve şeker giderim yeteneğini ve aynı zamanda $P$. sajor-caju dışındaki mantarların lakkaz aktiviteleri incelenmiştir [14]. Zeytin prinası ile sentetik boyaların (Metilen Mavisi, Kongo Kırmızısı ve Metil Turuncusu) sulu çözeltilerden adsorpsiyon prosesi içerisinde giderimi gerçekleştirilen bir çalışmada ise sırasıyla $\% 74,9, \% 56.8$ ve 70,1 giderim verimleri elde edilmiştir [12]. Yumurta kabuğu-kitosan modifiye ürünü (YKKMÜ) üzerine Brilliant Blue R (BBR) boyar maddesinin adsorpsiyon yöntemi ile giderimi konusunda yapılan bir çalışmada kesikli sistemde $\% 53,28$ sürekli sistemde ise $\% 91,01$ verim elde edilmiştir [5]. Diğer bir çalışmada ise Malahit yeşili boyar maddesinin adsorpsiyon araştırmasında pirina ile gideriminde 120 dakikada dengeye ulaşılarak artan konsantrasyon, sicaklik ve $\mathrm{pH}$ ile adsorplanan boya miktarının arttığı, iyonik şiddetin artması ile adsorpsiyonun azaldığ 1 tespit edilmiş, tüm deneysel şartlar altında maksimum adsorpsiyonun \% 98,69 olduğu belirlenmiştir [10].

$\mathrm{Bu}$ çalışmada zeytin endüstrisi çıktılarından çevresel bakımından katı atık niteliğinde bulunan pirinanın endüstrilerde yoğun olarak kullanılan boyar maddelerden Everzol Yellow 3RS (EY 176) gideriminde bir adsorban madde olarak etkinliği incelenmiştir. Pirinanın çevre açısından daha faydalı olabilmesi ve ekonomik açıdan pirinaya katma değer kazandırılması amaçlanmıştır.

\section{MATERYAL METOD}

Sentetik renkli atıksu olarak EY 176 boyar maddesi içeren çözeltisi $500 \mathrm{mg} / \mathrm{L}$ konsantrasyonunda stok çözelti hazırlanmıştır. Çalışma sırasında $50 \mathrm{mg} / \mathrm{L}$ boya çözeltileri, stok çözeltilerden saf su ile seyreltme yapılarak hazırlanmıştır. Boya çözeltilerinin $\mathrm{pH}$ ayarlamaları $0,1 \mathrm{~N} \mathrm{NaOH}$ ve 0,1 
$\mathrm{N} \mathrm{H}_{2} \mathrm{SO}_{4}$ çözeltileri kullanılarak yapılmıştır. Zeytin endüstrisi katı atığı 3 mm'lik elekle elenmiştir. Saf suyla y1kanmış, kurutulmuş ve tekrar saf suyla yıkanarak süzülmüştür. Etüvde $103{ }^{\circ} \mathrm{C}^{\prime}$ de 3 saat kurutulmuştur. Elde edilen pirina adsorban olarak kullanıma hazır hale getirilmiştir. Kesikli adsorpsiyon deneyleri $250 \mathrm{~mL}$ hacminde cam erlenlerde ve bir 1sitmalı çalkalayıcı (ZHWY200B, ZHICHENG Analytical Co., Ltd, Çin) içerisinde gerçekleştirilmiştir.

Karıştırma işlemlerinden sonra numuneyi adsorban maddeden ayırmak için $0,45 \mu$ m'lik membran filtreler (Millipore Corp., Bedford, Mass.) kullanılmıştır. Süzülen numunelerin adsorbans değerlerini okumak için Hach Lange DR 2800 model Spektrofotometre kullanılmıştır.

Çözelti ortamından uzaklaştırılan boyar madde miktarlarının hesaplanmasında (1) numaralı eşitlikten faydalanılmıştır.

$$
\mathrm{q}_{\mathrm{t}}(\mathrm{x} / \mathrm{m})=\left(\mathrm{C}_{0}-\mathrm{C}_{\mathrm{e}}\right) . \mathrm{V} / \mathrm{W}
$$

Burada; qt: Adsorban maddenin birim ağırlığı başına adsorplanan boyar madde miktarı $(\mathrm{mg} / \mathrm{g}), \mathrm{x}$ : Adsorplanan boyar maddenin kütlesi (mg), $\mathrm{m}$ : Adsorban maddenin kütlesi (g), $\mathrm{C}_{0}$ : Boyar maddenin başlangıç konsantrasyonu $(\mathrm{mg} / \mathrm{L}), \mathrm{C}_{\mathrm{e}}$ : Adsorpsiyon sonrası çözeltide kalan boyar madde konsantrasyonu $(\mathrm{mg} / \mathrm{L})$, V: Kullanılan çözelti hacmi (L), W: Kullanilan adsorban maddenin miktarı (g) dır [15]. Araştırma deneylerinde kullanılan reaktif boya Everzol Yellow 3RS H/C (C.I. Reactive Yellow 176, $\lambda \max =400 \mathrm{~nm}$ ) bazik özellikteki azo boya grubundan ve anyonik sülfonat grubuna ait olduğu bilinmektedir $[16,17]$.

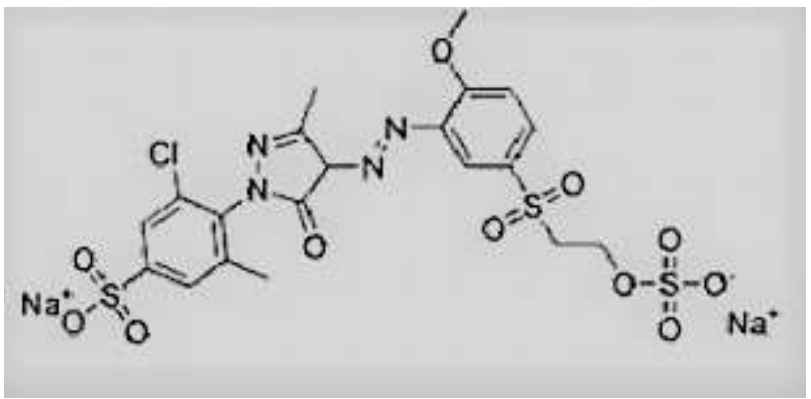

Şekil 1. C.I. Reactive Yellow 176 boyasının kimyasal formülü [18].

\section{ARAŞTIRMA SONUÇLARI VE TARTIŞMA}

Zeytin endüstrisi atığı (pirina) ile tekstil boyalarından olan Everzol Yellow 3RS isimli boyanın sulu çözeltiden giderim etkinliği araştırılmıştır. Optimum denge şartlarının belirlenebilmesi için, temas süresi, adsorban dozu, karıştırma hızı, ortam sıcaklığı ve $\mathrm{pH}$ değerine bağlı olarak boya giderim verimleri incelenmiştir.

Şekil 2'de adsorpsiyon işlemine adsorban dozu etkisi ve sistemde uygun kabul edilebilecek doza karşılık renk giderim verimi yaklaşık \%70-80 civarı olduğu görülmektedir. Burada adsorban dozu artırıldığında ilk önce renk giderim verimi artmakta ve sonrasında dengeye ulaşmaktadır. Fakat optimum yani kabul edilecek değer olarak $0,6 \mathrm{~g} / 250 \mathrm{~mL}$ uygun olacağ belirlenmiştir. Şekil 3 'de adsorpsiyon işlemine temas süresinin etkisi ve sistemin dengeye gelme süresi görülmektedir. Süre olarak 30-330 dakika aralığında araştırma gerçekleştirilmiş olup 150 dakika temas süresi olarak uygun olacağı belirlenmiştir. Şekil 4'de adsorpsiyon sırasındaki $\mathrm{pH}$ değişiminin renk giderim üzerine etkisi ve sistemdeki değişim görülmektedir. Çalışma pH'ının değişikliği hem ihtiyaç olan baz ve asit sarfiyatını artıracak olması yüzünden renk giderim veriminin nötr aralıklarda kalmasının daha uygun olacaktır. pH değerinin 7,5 olarak uygun olacağ 1 belirlenmiştir. Şekil 5'de adsorpsiyon işlemine sırasında karıştırma etkisi ve renk giderim yüzdeleri görülmektedir. 100-400 rpm aralığında çalışma gerçekleştirilmiştir. Hızın artması pirina ile renk pigmentlerinin temas etme olasılığını artırdığ 1 için renk giderim verimi de artmaktadır. Fakat karıştırma işlemi saha uygulamalarında veya büyük su kütleleri için yüksek miktarlarda enerji ihtiyacına ve ekipman gücü gerektirmesi durumuna karşıı $400 \mathrm{rpm}$ yerine 250 rpm hızın daha uygun olabileceği düşünülmüştür. 


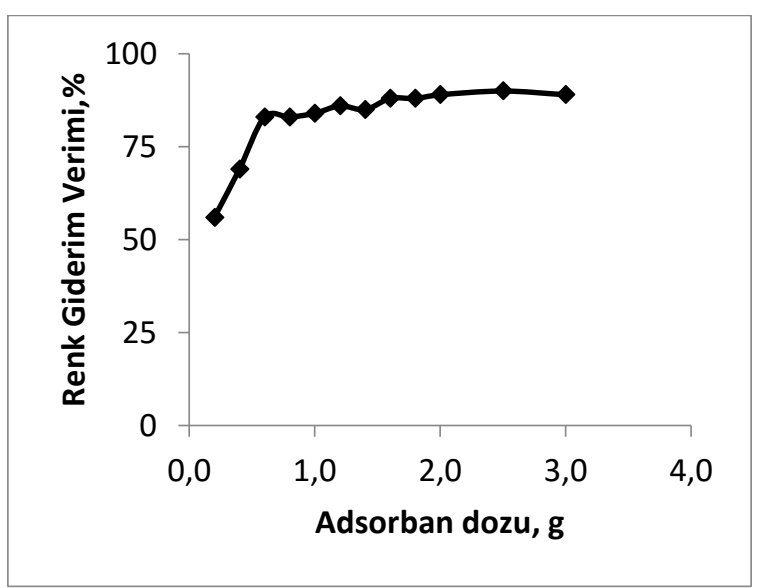

Şekil 2. EY 176 boyasına ait adsorban dozuna karşılık renk giderim eğrisi (200 rpm, $298 \mathrm{~K}, 120$ dakika, orj. pH).

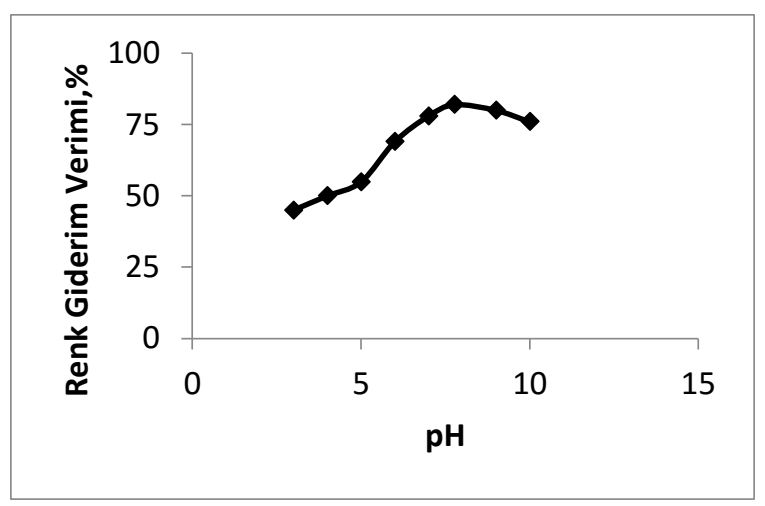

Şekil 4. EY 176 boyasına ait $\mathrm{pH}$ değerine karşılık renk giderim eğrisi $(200 \mathrm{rpm}, 298 \mathrm{~K}, 0,6 \mathrm{~g} / 250 \mathrm{~mL}$ pirina, 150 dakika).

Pirina üzerinde yapılan adsorpsiyon çalışması ile adsorpsiyon verimliliğinin olduğunu ve artan boya konsantrasyonu ile adsorpsiyon kabiliyetinin azaldığını göstermiştir. Adsorpsiyon işlemlerinin sonucu olarak, 150 dakika, 250 rpm karıştırma hızı, pH 7,7, $25{ }^{\circ} \mathrm{C}$ sicaklik ve $0,6 \mathrm{~g} / 250 \mathrm{~mL}$ adsorban madde / boya oran 1 (\% 80 üzerinde giderim verimi) belirlenmiştir. Adsorbanın birim ağırlığı başına adsorplanan boyar madde miktarı $17.5 \mathrm{mg} / \mathrm{g}$ olarak hesaplanmıştır.

\section{TEŞEKKÜR VE BİLGI}

Çalışmanın gerçekleştirilebilmesi sırasında yazarlar eşit görev almış olup çalışmamızın bir

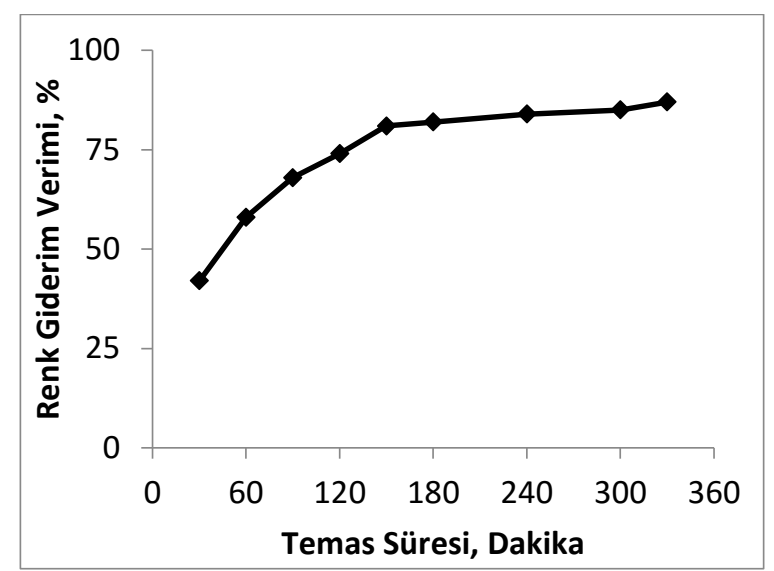

Şekil 3. EY 176 boyasına ait temas süresine karşılık renk giderim eğrisi ( $200 \mathrm{rpm}, 298 \mathrm{~K}, 0,6 \mathrm{~g} / 250 \mathrm{~mL}$ pirina, orj. $\mathrm{pH})$.

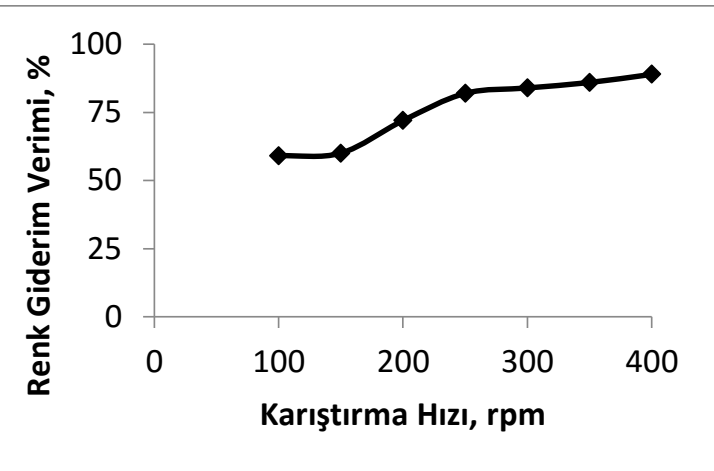

Şekil 5. EY 176 boyasına ait karıştırma hızına karşılık renk giderim eğrisi ( $\mathrm{pH} 7-8$ aralı̆̆ 150 dakika).

kısmı International Conference on Civil and Environmental Engineering (ICOCEE Cappadocia) isimli konferansta sözlü olarak sunulmuştur.

\section{KAYNAKLAR}

[1]. Judd S., Jefferson B. The textile industry, Mem. Ind. Wastewater Recovery Re-use 2003; 132-158.

[2]. Namasivayam C., Muniasamy N., Gayatri K., Rani M., Ranganathan K., Removal of Dyes from Aqueous Solutions by Cellulosic Waste Orange Peel, Bioresour. Technol. 1996; 57: 37-43. 
[3]. Yıldız A. Reaktif Azo Boyanın Kitosan ile Adsorpsiyon Kinetiğinin İncelenmesi. Yüksek Lisans Tezi, Kocaeli Üniversitesi Fen Bilimleri Enstitüsü, Kocaeli, 2008.

[4]. Erdem B. Na-Bentonit ve Organo-Bentonit Üzerine Boya Adsorpsiyonunun İncelenmesi. Yüksek Lisans Tezi, Anadolu Üniversitesi Fen Bilimleri Enstitüsü, Eskişehir, 2004.

[5]. Koçabaş B. Yumurta Kabuğu-Kitosan Modifiye Ürünü Kullanilarak Atık Sulardan Brilliant Blue $\mathrm{R}$ Boyar Maddesinin Adsorpsiyon Yöntemi ile Gideriminin İncelenmesi, Yüksek Lisans Tezi, Hitit Üniversitesi, Fen Bilimleri Enstitüsü, Çorum, 2015.

[6]. Öden M.K., Özdemir C. Effect of Temperature and $\mathrm{pH}$ by Adsorption of Methylene Blue onto Natural Boron Ore, Journal of Selçuk University Natural and Applied Science, 2013; p: 89-95.

[7]. Acemioğlu, B., Adsorption of Congo Red from Aqueous Solution onto Calcium-Rich Fly Ash, Journal of Colloid and Interface Science 2004; 274: 371-379.

[8]. Kalipci E., Sahinkaya S., Dortkol M., Aras S. Decolorization of Basic Textile Dyes Using a Novel Adsorbent Modification Method: Ultrasonic-Acid Modification, Int. J. Environ. Res., 2016; 10(1): 31-40,

[9]. Öden M.K., Özdemir C. Removal of Methylene Blue Dye from Aqueous Solution Using Natural Boron Ore and Leach Waste Material: Adsorption Optimization Criteria, International Journal of Current Research and Academic Review, ISSN: 2347-3215 Special Issue-1 (October-2014) pp. 66-71.

[10]. Koçer O. Zeytin Posası (Pirina) Üzerine Malaşit Yeşili'nin Sulu Çözeltiden Adsorpsiyonu, Yüksek Lisans Tezi, Kilis 7 Aralik Üniversitesi, Fen Bilimleri Enstitüsü, Kilis, 2013.
[11]. Dağdelen S. Remazol Brillant Blue R Boyasının Sulu Çözeltiden Uzaklaştırılması İçin Zeytin Posasının (Pirina) Adsorbent Olarak Kullanımının Araştırılması, Yüksek Lisans Tezi, Kilis 7 Aralık Üniversitesi, Fen Bilimler Enstitüsü, Kilis, 2012.

[12]. Alı K. Zeytin Prinasi ile Sentetik Boyaların Sulu Çözeltilerden Giderimi, Yüksek Lisans Tezi, Selçuk Universitesi, Fen Bilimleri Enstitüsü, Konya, 2016.

[13]. Rizzi V., D'Agostino F., Fini P., Semeraro P., Cosma P. An Interesting Environmental Friendly Cleanup: The Excellent Potential of Olive Pomace for Disperse Blue Adsorption/Desorption from Wastewater, Dyes and Pigments 2017; 140: 480-490.

[14]. Yeşilada Ö., Şık S., Şam M. Treatment of Olive Oil Mill Wastewater With Fungi, Tr. J. of Biology 1999; 23: 231-240.

[15]. Zhang Z., Zhang Z., Fernandez Y., Menendez J.A., Niu H., Peng J., Zhang L., Guo S. Adsorption Isotherms and Kinetics of Methylene Blue on a Low-Cost Adsorbent Recovered from a Spent Catalyst of Vinyl Acetate Synthesis. Applied Surface Science, 2010; 256: 2569-2576.

[16]. Armağan B., Turan M., Çelik M. Modifiye Sepiyolit ve Zeolitin Tekstil Endüstrisi Atiksularinda Adsorbant Olarak Kullanilmasi: Karşilaştirmali Değerlendirme, V. Ulusal Çevre Mühendisliği Kongresi, Ankara, 2003.

[17]. Ozdemir O., Armağan B., Turan M., Çelik M., Comparison of The Adsorption Characteristics of Azo-Reactive Dyes on Mezoporous Minerals, Dyes and Pigments 2004; 62: 49-60

[18]. Kuleyin A., Aydin F. Removal of Reactive Textile Dyes (Remazol Brillant Blue R and Remazol Yellow) by Surfactant-Modified Natural Zeolite. Environ. Prog. Sustainable Energy, 2011; 30: 141-151. doi:10.1002/ep.10454. 